\title{
Common problematic aspects of coupling hydrological models with groundwater flow models on the river catchment scale
}

\author{
R. Barthel \\ Institute for Hydraulic Engineering, Universitaet Stuttgart, Germany \\ Received: 23 January 2006 - Revised: 22 May 2006 - Accepted: 3 July 2006 - Published: 26 September 2006
}

\begin{abstract}
Model coupling requires a thorough conceptualisation of the coupling strategy, including an exact definition of the individual model domains, the "transboundary" processes and the exchange parameters. It is shown here that in the case of coupling groundwater flow and hydrological models - in particular on the regional scale - it is very important to find a common definition and scale-appropriate process description of groundwater recharge and baseflow (or "groundwater runoff/discharge") in order to achieve a meaningful representation of the processes that link the unsaturated and saturated zones and the river network. As such, integration by means of coupling established disciplinary models is problematic given that in such models, processes are defined from a purpose-oriented, disciplinary perspective and are therefore not necessarily consistent with definitions of the same process in the model concepts of other disciplines. This article contains a general introduction to the requirements and challenges of model coupling in Integrated Water Resources Management including a definition of the most relevant technical terms, a short description of the commonly used approach of model coupling and finally a detailed consideration of the role of groundwater recharge and baseflow in coupling groundwater models with hydrological models. The conclusions summarize the most relevant problems rather than giving practical solutions. This paper aims to point out that working on a large scale in an integrated context requires rethinking traditional disciplinary workflows and encouraging communication between the different disciplines involved. It is worth noting that the aspects discussed here are mainly viewed from a groundwater perspective, which reflects the author's background.
\end{abstract}

Correspondence to: R. Barthel

(roland.barthel@iws.uni-stuttgart.de)

\section{Introduction}

Model coupling (or rather, model concepts) on a large or regional scale $\left(\sim 10^{4}-10^{5} \mathrm{~km}^{2}\right)$ is a common task in modern integrated water resources management (IWRM). It has become apparent - in particular in Global Change research - that processes must inevitably be perceived in an integrated way. The impacts of climate change can not be evaluated meaningfully without considering, for example, land use changes (subsequent or independent) or other natural and socio-economic developments. As fully integrated holistic model concepts (i.e. models which do not just comprise several individual "old" models) for this purpose do not exist (yet), one means of integration is the coupling of existing disciplinary models. Problems arise here because disciplinary models were usually originally designed to solve specific problems in different domains of the water cycle. The processes and the process descriptions they include and the extent of their domain of interest was adapted to a typical class of problems. Therefore the coupling of two or more disciplinary models is associated with conceptual inconsistencies and incompatibilities because the individual models may describe the same process differently, may ignore important connecting processes or overlaps and gaps between the model domains may exist. This paper cannot cover the field of model coupling in hydrology extensively. A broad overview is given by Bronstert et al. (2005).

GLOWA-Danube (http://www.glowa.org) and Rivertwin (http://www.rivertwin.org) are interdisciplinary, international projects that attempt to develop integrated strategies and tools for water and land use management. Within these projects the author's research group is responsible for the groundwater domain and its connections to the other domains of the hydrological cycle as well as to human activities. After approximately five years of intensive development of strategies to couple groundwater models to SVAT (soil-vegetation-atmosphere-transfer) and hydraulic

Published by Copernicus GmbH on behalf of the European Geosciences Union. 
and hydrological models on the very large scale (catchments of 80000 and $14000 \mathrm{~km}^{2}$, respectively the Danube and Neckar), it has become apparent that the concept of interdisciplinary model coupling requires a new outlook on certain aspects of the hydrological cycle.

It is shown here that it is crucial to include several considerations in the coupling strategy to achieve any valuable coupling of hydrological and groundwater models; it must be ensured that processes, parameters, model discretisation (spatial and temporal) are defined coherently on either side. Neither gaps nor overlaps of model domains and processes may exist. The scale and context dependency of models must be considered, in particularly with regard to the anticipated applications of the coupled (or integrated) model. In this paper, two terms that are usually of great importance in the attempt to relate surface and subsurface processes were chosen to demonstrate the importance of the aforementioned considerations: groundwater recharge and baseflow (or groundwater runoff/discharge; from here on regarded as synonyms even though distinctions would be possible). These apparently well-known, well-defined terms are, if analysed in detail, highly dependent on scale and context. Moreover they are understood differently in "surface" and "subsurface hydrology" (groundwater, saturated flow, hydrogeology etc.) depending on the main focus of interest (saturated - unsaturated flow processes etc.). As will be shown later, it is of significance whether we look at groundwater recharge mainly as something getting into the saturated zone or as something leaving the unsaturated zone. A detailed analysis of this aspect reveals a "forgotten domain" of the hydrological cycle that has neither gained much interest from groundwater nor unsaturated zone researchers: the deeper unsaturated zone, located between the bottom of the root zone and the groundwater level (or aquifer top in case of a confined situation), see Harter and Hopmans (2004) for a detailed discussion.

Before starting a detailed description of the problem, some terms - as they are used in the context of this paper - will be defined. A catchment refers to river catchments in the range of $10^{3}$ to $10^{5} \mathrm{~km}^{2}$ and more. This scale is referred to as "regional". A system means a main component or domain of the hydrological cycle (compartment); e.g. the "groundwater system", or the "unsaturated zone (system)"," The term model includes both the actual model, as one representation of a real natural system, as well as the "model concept" (a mathematical or verbal formulation of processes without reference to a certain location). In this paper, Groundwater models are flow models that simulate piezometric heads, flow directions and fluxes in one or more aquifers, discretized in grids or elements according to the actual geometry of geological layers. Groundwater models as introduced here are limited to simulation of saturated zone processes. Hydrological models are less specifically defined as models that simulate the water cycle of a catchment with a focus on processes near the land surface, including soil and the unsaturated zone but not describing the groundwater system ex- plicitly. This definition may include everything from simple black box models to highly parameterized physically based models. Finally, parameter refer to (dimensionless) calibration parameters, whereas variables define measurable quantities (physical parameters). The author is aware of the fact that using the terms "parameter" and "variable" in this way might be misleading, since they are used differently by different disciplines. According to the author's experiences from interdisciplinary projects, it is crucial to define these seemingly "common sense terms" in order to avoid severe misunderstandings and subsequently bad model results.

Finally the term model coupling itself has to be defined: Model coupling here means coupling of distinct existing models or model concepts that were developed to simulate processes in one "system", e.g. coupling of a typical model concept for the saturated zone (MODFLOW; McDonald and Harbaugh, 1988) with a typical hydrological model concept (HBV; Bergström, 1995). Coupling in the present context mainly means coupling via exchange variables rather than directly coupling process equations and code (see Fig. 1).

\section{Model coupling on the large scale}

Coupling of models on the regional scale is relatively new and no generalised concepts exist. The problems and issues are manifold, in particular since each catchment and each problem has its special characteristics and requirements. Therefore a detailed consideration is not possible here. It is however necessary to at least mention the most important issues in order to make clear, that those aspects dealt with in more detail later are only two out of many. Considerations related to model coupling on the large scale can be classified in three main categories:

1. Aspects related to modelling on the large scale in general

\section{Aspects related to model coupling in general}

3. Specific aspects related to model coupling on the large scale

Aspects of the first category are: data requirements and data availability, discretisation and scaling aspects (processes, variables and parameters) and computational demands. It is worth mentioning here that even if the model is quite fast a thorough analysis of the huge amounts of model result data beyond looking at performance criteria can be very time consuming. Since these problems are well known and not very specific, they will not be dealt with from here on.

The second group of aspects is related to coupling of systems that are governed by different processes and variables (and consequently equations) and that have different focal points on spatial and temporal scales. A lot of research has 


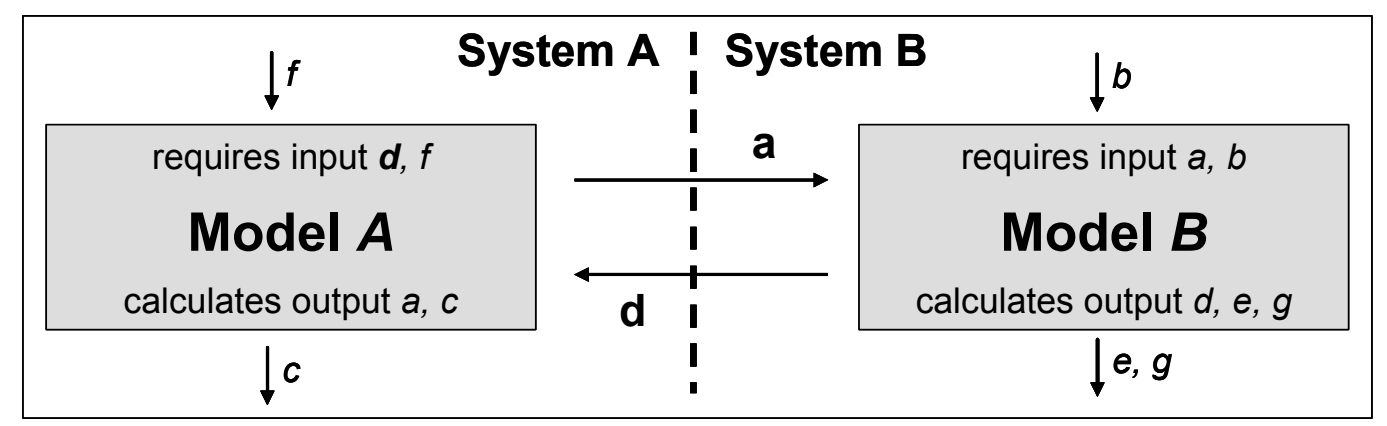

Fig. 1. Coupling two models using exchange variables, where some of the output variables of one model form input variables for the other. $a$ and $d$ are exchange variables used for coupling.

been dedicated to these aspects (see e.g. Bronstert et al., 2005). Again, no further discussion is made here.

Finally the third group combines the problems acknowledged from the first two groups and adds new ones. In the author's opinion, the most eminent issue in coupling models on a large scale (third category aspects) seems to be the need for a real joint model calibration. Joint calibration in general should be beneficial (at least theoretically) because it allows calibration against more than one output variable (e.g. Seibert, 2000). This advantage however decreases quite rapidly as the model area increases due to the computational capacity required. Large scale groundwater flow models are usually quite slow. As a consequence, automatic, iterative calibration and optimisation procedures can not usually be applied successfully.

\section{Development of coupling strategies}

Within the scope of this paper, it is assumed that the basic coupling strategy is as shown in Fig. 1. Model $A$, which represents system A, calculates an output which forms an input for model $B$ (system B). It is furthermore assumed that the coupling strategy is mainly based on the use of existing model concepts rather than on the development of new ones. For the remaining part of this paper Model $A$ is a hydrological model, Model $B$ represents a groundwater flow model.

The first step in attempting to couple two models that describe different but interdependent systems should be the consideration of some basic questions. They include the questions that should generally be asked before starting to model. These questions relate to the problems the coupled model complex will be used to solve, the output variables that are required, the relevant scales, the required accuracy of the results, the data availability etc. As considering these general question should be a standard procedure in model conceptualisation, the topic is not elaborated on.

In addition to these general issues there are a number of questions that relate specifically to model coupling of two systems:
- How are the individual systems defined and what are the (dominant) processes that take place in each system?

- Where and what is the boundary between the systems? Is it a sharp and stable or just a virtual, time-dependent boundary?

- Which processes connect the systems to each other? Are the connecting processes clearly related to processes that take place within the individual systems?

- Which process descriptions are needed, which are available, which are applicable in view of discretisation and data availability?

- What are the dynamic relations between the two systems (one or bi-directional, feedback, different dynamics)?

- Which measurable quantities are available to determine the effect of changes in inputs to the individual system and how do these quantities relate to the connecting processes?

- What are the relevant process scales (time and space) and how are they related to the scale of the problem? Are the relevant scales equal on either side?

Answers to the questions listed above should lead to the definition of system boundaries, connecting processes, exchange variables and appropriate scales and finally to a first conceptual description of at least one possible coupling approach.

Once such a conceptualization has been achieved, the next step is to choose (or to develop) the appropriate individual models for each system: "Appropriate" means that the models treat their domain in a way that satisfies the answers to the questions listed above. Whereas internal processes are of minor importance here, the exchange processes and variables require special attention. From Fig. 1 it is clear that an input variable $d$ of model $A$ must be equal to the output variable $d$ of model $B$. In this case, equal means not 


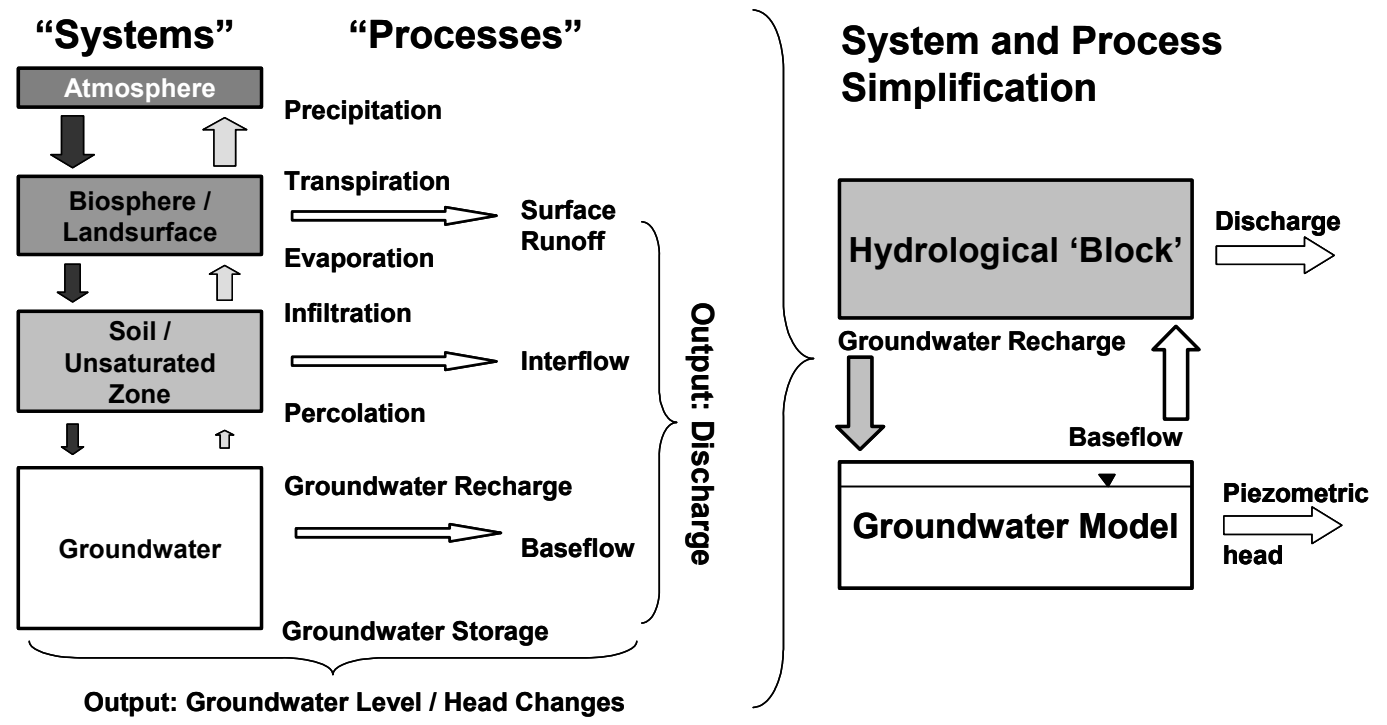

Fig. 2. Fundamental systems and processes that are typically considered when groundwater and surface water/unsaturated zone systems are coupled.

only equal units and equal spatial and temporal discretisation - in most cases it will not be too problematic to adjust these values formally by means of conversion, aggregation and dis-aggregation. What is far more important and at the same more difficult to achieve is guaranteeing equality of the exchange variable with respect to "meaning". Does $d$ calculated by model $B$ really have the same meaning as $d$ required by $A$ ? Is it conceptually the same thing?

In the case of coupling hydrological and groundwater models, the first step in developing the coupling strategy, i.e. the identification of systems and connecting processes is conceptually quite difficult if all possible processes on all scales are to be considered. In the context of this paper however certain simplifications are made: Firstly it is assumed that the effects of direct evaporation from groundwater, capillary rise, and root water uptake from groundwater (all flows out of the groundwater upwards) can be neglected. We also will assume that fluxes from the 'surface water' system (rivers) to the groundwater system are small compared to fluxes in the opposite direction. This allows us to ignore certain complicated, non-linear and interdependent feedback processes.

Given these assumptions, the hydrological cycle can be simplified to the situation shown on the right hand side of Fig. 2: a system reduced to a hydrological block (model) and a groundwater block (model) which is consistent with the scheme shown in Fig. 1. The two connecting processes are groundwater recharge, as the quantity leaving the unsaturated part and entering the groundwater system, and baseflow as the part leaving the groundwater and entering the surface water system. When all the assumptions and generalisations mentioned above are considered, an apparently simple and straight forward coupling principle can be established. How- ever, if we have a closer look at this simple scheme we will find that is conceptually problematic because of the weak definitions of the terms it is founded on.

\section{Groundwater recharge and baseflow - definition and characteristics}

As shown in the previous section, groundwater recharge and baseflow are two main processes that link the unsaturated and saturated zones or, in a more specific sense, the link between hydrological and groundwater models. Using the balance terms controlled by these two processes along with interflow and surface runoff, it is seemingly possible to close the hydrological balance of a catchment. Of course storage in the different compartments of the system (groundwater, soil and delayed discharge in the surface and river runoff) also has to be considered.

It is well known that neither groundwater recharge nor baseflow can be measured directly because it is largely unknown where and how these processes take place and because these processes are inaccessible for measuring procedures or cannot be clearly separated from others. Less well known is the fact that no common definition that would be meaningful in the context of large scale models exists for either of these terms. Proof of this is the existence of a large number of methods to determine groundwater recharge as well as baseflow. The methods are conceptually very different and accordingly yield very different results. Groundwater recharge can be directly calculated using physically based approaches (unsaturated flow equations, tracers, chemistry, isotopes ...) or indirectly using conceptual models 


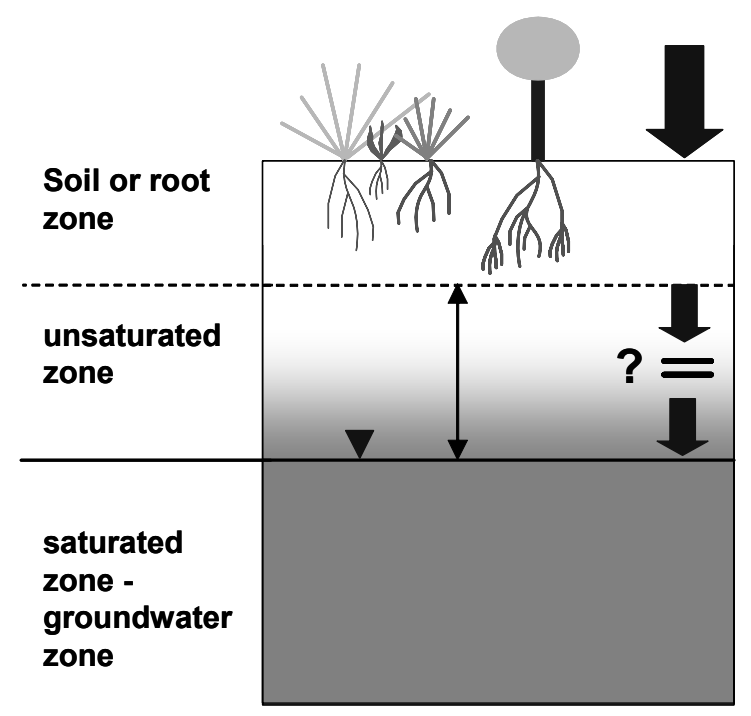

Precipitation

Infiltration

Percolation

Groundwater Recharge Type 1: Definition

used in many physically based unsaturated

zone models (also: lysimeters)

Groundwater Recharge Type 2:

Standard definition used

in groundwater modelling

Fig. 3. Groundwater recharge - two contrary conceptual interpretations. Type 1: water leaving the root zone, Type 2: water entering the saturated zone.

(for an overview of state-of-the-art methods see: de Vries et al., 2002). Baseflow is usually determined using conceptual approaches (hydrograph separation, e.g. Tallaksen, 1995) in rare cases also using hydrochemical and isotopical methods but is also calculated, using groundwater models, as the amount of water flowing towards a river boundary condition. There is a lot of evidence coming from different studies worldwide that the results of most approaches used to determine the groundwater contribution to river discharge are highly unreliable or at least only valid under very specific conditions for specific catchments (see e.g. Halford and Mayer, 2000; Vogel and Kroll, 1995).

One reason why so many different methods were established is the actuality of contrasting catchment characteristics and different data availability as well as different scales of application. At the same time, diverse approaches are the result of a different understanding of what recharge and baseflow really are. Conflicting view points across different disciplines can be recognized. In the case of groundwater recharge, two extreme interpretations can be identified:

Groundwater recharge is usually defined as the sum of all inflows to a groundwater system or aquifer. From the groundwater standpoint, this includes all inflows from above, from below and lateral inflows. Only under very specific conditions it is possible to measure or calculate all these recharge terms. Therefore even groundwater experts almost always reduce the recharge definition in practice to the inflows coming from above (precipitation, effluent rivers). But still their focus is usually on the volume of water entering a (specific) aquifer. On the other hand, surface hydrologists and soil scientists usually suppose groundwater recharge to be the amount of water leaving the soil or root zone, since this is the domain they predominantly deal with (see Scanlon et al.,
2002). The basic assumption here is: When water leaves the domain influenced by vegetation (roots) and evaporation (capillary rise etc.) vertically downwards, it will reach the groundwater eventually and must therefore be equivalent to groundwater recharge. Figure 3 exemplifies these two contradictory views:

According to Fig. 3, it would be valid to assume that groundwater recharge defined as "root zone percolation" and groundwater recharge defined as "water entering the saturated zone" describe the same quantities volumetrically. This is only true if volumes are averaged over a longer period of time, since depending on the distance between the root zone bottom and the groundwater surface, a temporal delay occurs.

Figure 3 shows a very specific situation with a shallow groundwater table (thickness of root zone and the total thickness of the unsaturated zone are of the same order of magnitude), a completely flat relief and homogenous, isotropic conditions. On a larger scale it is highly unlikely that conditions like this are realized everywhere in a catchment. On a large scale, relief will be present and the subsurface will usually show heterogeneity. Under such conditions, the scheme shown in Fig. 3 must be replaced with the scheme shown in Fig. 4.

Figure 4 shows a still idealized, simple situation but is more realistic with respect to formation of groundwater recharge. It becomes obvious that in an area with relief, the depth to the groundwater is a relevant factor for any transient model (Fig. 4, left side). Of even greater influence however are heterogeneities such as impermeable or less permeable layers that occur in the unsaturated part between root zone and groundwater (Fig. 4, right side). Such layers of lower permeability can be found everywhere and the deeper the 
Assumption: precipitation and infiltration: homogeneously all over the area

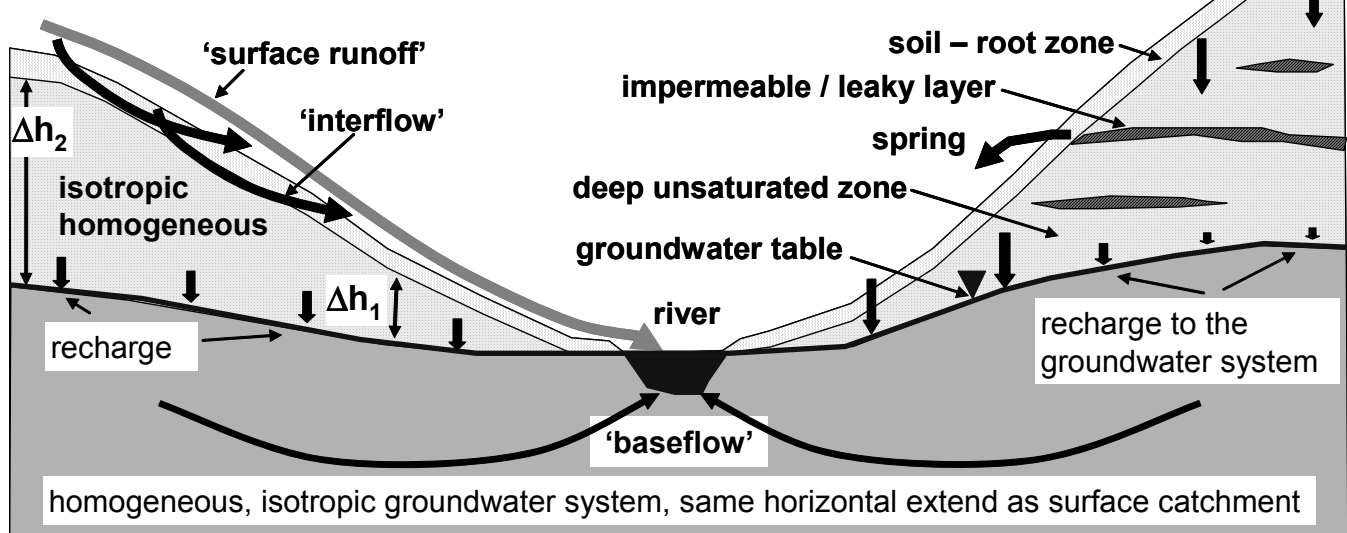

Fig. 4. More realistic (compared to Fig. 3) but still highly conceptual view of land surface, soil and groundwater processes.

depth to the groundwater is, the more frequent and the more effective they usually are. They lead to the formation of saturated lenses (perched water) and subsequently to horizontal flow in the deeper unsaturated or partly saturated zone. Flow can be towards neighbouring catchments or can lead to the formation of springs. In either case, the flow does not reach the groundwater system and must therefore not be considered as groundwater recharge.

At this point, a definite gap in the two groundwater recharge definitions in Fig. 3 becomes apparent: If less permeable layers are present - or anisotropic, heterogeneous conditions in general, the recharge actually reaching the groundwater system must be smaller than the recharge leaving the soil/root zone. The horizontal flow induced by the structures in the deep unsaturated zones can cause an overall loss of water from the catchment under investigation or becomes interflow (i.e., it reaches the surface water system without having been part of the groundwater system after a passage through the unsaturated zone).

The key to this problem would be a better understanding or at least a thorough recognition of the conditions and the processes within the deeper unsaturated zone, which was previously named here a "forgotten domain" in hydrological sciences (Harter and Hopmans, 2004). This zone, located between the bottom of the "root zone" and the groundwater level (or aquifer top in the case of a confined situation) can be of considerable thickness on the regional scale (relevant in the range of 10 to $1000 \mathrm{~m}$ ) and can lead to a difference of up to $100 \%$ between root zone percolation and actual recharge to a regional aquifer (see e.g. Rauert et al., 1993; Andres and Egger, 1985). In practical groundwater modelling this is a well known fact (see e.g. Sanford, 2002), however the approaches to deal with this problem (transfer functions) are usually of highly pragmatic rather than of scientific nature (see e.g. Lemmelä and Tattari, 1998; Tankersley et al., 1993).
In the previous section it was concluded, that on the large scale at least a part of the water that percolated through the root zone becomes "interflow" after it has been forced to flow horizontally due to less permeable structures (see Fig. 4). In the course of this conclusion, a second problematic aspect becomes apparent; the question of when a saturated domain should be considered as "groundwater" and subsequently when a flow in a saturated domain should be named groundwater flow (baseflow [?]) or better interflow? In the case of Fig. 4 on right hand side, infiltrating water seeps through the unsaturated zone until it reaches an impermeable layer. Here it accumulates and forms a (small [? $\rightarrow$ scale!]) saturated lens. Depending on the hydraulic conditions within this lens eventually saturated flow (groundwater flow [?]) will be established. Whether such a perched (small) saturated lens is considered to be groundwater or if it should be called a (small) saturated domain in a predominantly unsaturated zone now depends on the situation, i.e. the scale and the context. This also determines whether the resulting flow is called "interflow" or "groundwater flow" (baseflow).

The definition of groundwater, in particular in a modelling context is a highly scale-dependent one. Obviously not any perched or local aquifer or small saturated domain of some $\mathrm{m}^{3}$ can be taken into account as groundwater in a regional groundwater flow model, even if the processes within this saturated domain are dominantly saturated flow processes. Figure 5 demonstrates how a clear definition of groundwater as a saturated domain becomes questionable when the relevant scale changes over several orders of magnitude. It also shows how a seemingly clearly defined term such as groundwater recharge becomes ambiguous when regarded on different scales and in different contexts - depending on which aquifer is relevant for the specific problem. Finally it shows that recharge is not only a question of volume but also of time. Even if the recharge averaged over long periods might 


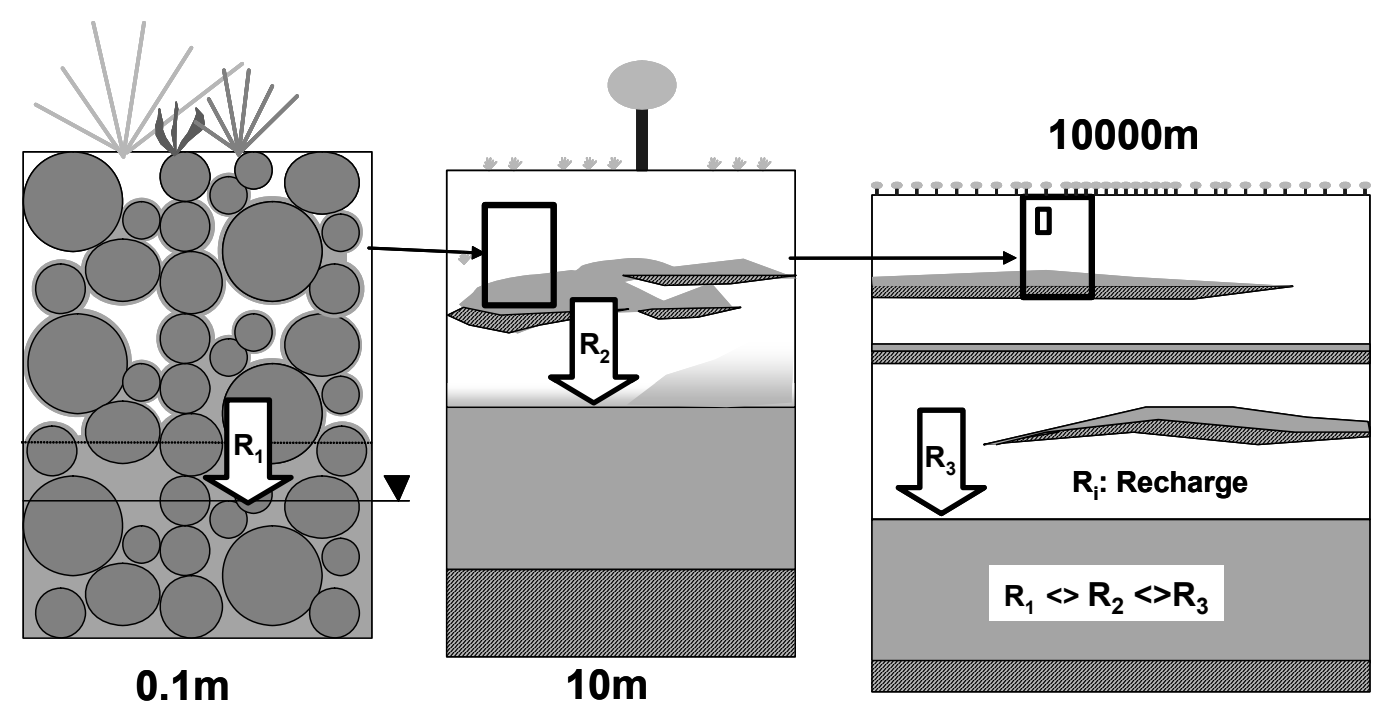

Fig. 5. Groundwater defined at different scales. The relevant definition in groundwater modelling depends highly on the size of the model domain and the discretisation. $\mathrm{R}_{1}$ to $\mathrm{R}_{3}$ show the relevant groundwater recharge for each of the relevant aquifers (scales).

be the same, its temporal relation to climatic events (climate change) might be completely different.

The scale dependency of definitions and the view point of the definitions identified so far (Figs. 3, 4) imply that the second process of interest, which is baseflow (see Fig. 2), should show analogous dependencies. The problem of finding a "true" definition for baseflow is explained schematically in Fig. 6.

According to Fig. 6 the definition of baseflow, depends on:

a) the river (stream order, gauge etc.) that is considered in the hydrological model (less relevant if the model is merely conceptual),

b) the aquifer or aquifers described by the groundwater flow model and

c) the scale, the discretisation and the context of the models.

Whereas in a conceptual hydrological model it is completely irrelevant where baseflow comes from (it is just a "slow" runoff component) baseflow in a groundwater flow model must be exactly the volume of water flowing into an explicitly defined river, that infiltrated from the explicitly defined aquifers of the groundwater flow model. The same applies for groundwater recharge: Recharge $R_{1}$ in Fig. 6 is not equal to recharge $R_{3}$ and therefore not applicable as recharge in a groundwater model that considers only the large scale regional aquifer shown at the bottom of Fig. 6 . Each "'recharge" and "baseflow" has to be related to specific aquifers.

\section{Conclusions}

In this short discussion, some common problematic aspects of coupling groundwater flow models and hydrological models (in a broader sense) were described. Coupling of such models is required in IWRM and Global Change research; furthermore it becomes apparent that the demand for model coupling rises with the size of the model area and the length of the period that is simulated. It was shown that the two main processes that connect surface and subsurface hydrological systems are groundwater recharge and baseflow (assumed here to be a synonym to groundwater runoff). Consequently it was stated that these two processes can be used to couple surface and subsurface models, i.e. hydrological and groundwater flow models. Groundwater recharge is an output of hydrological models and forms an input (time variant boundary condition) for groundwater flow models. Baseflow is calculated by groundwater flow models and is used as an input for hydrological models.

In a next step, it was shown that the definition and meaning of both groundwater recharge and baseflow depend on disciplinary view points and additionally on the scale, discretisation and context of the modelling task. Groundwater recharge as often defined in SVAT models is not necessarily the same as groundwater recharge required by a regional groundwater flow model. Baseflow calculated by a groundwater flow model is not necessarily the baseflow a conceptual hydrological or a hydraulic river model assumes. It is therefore necessary to define these exchange processes and variables (and how they are calculated and used) very carefully in all stages of model development and calibration in order to avoid severe modelling errors. 


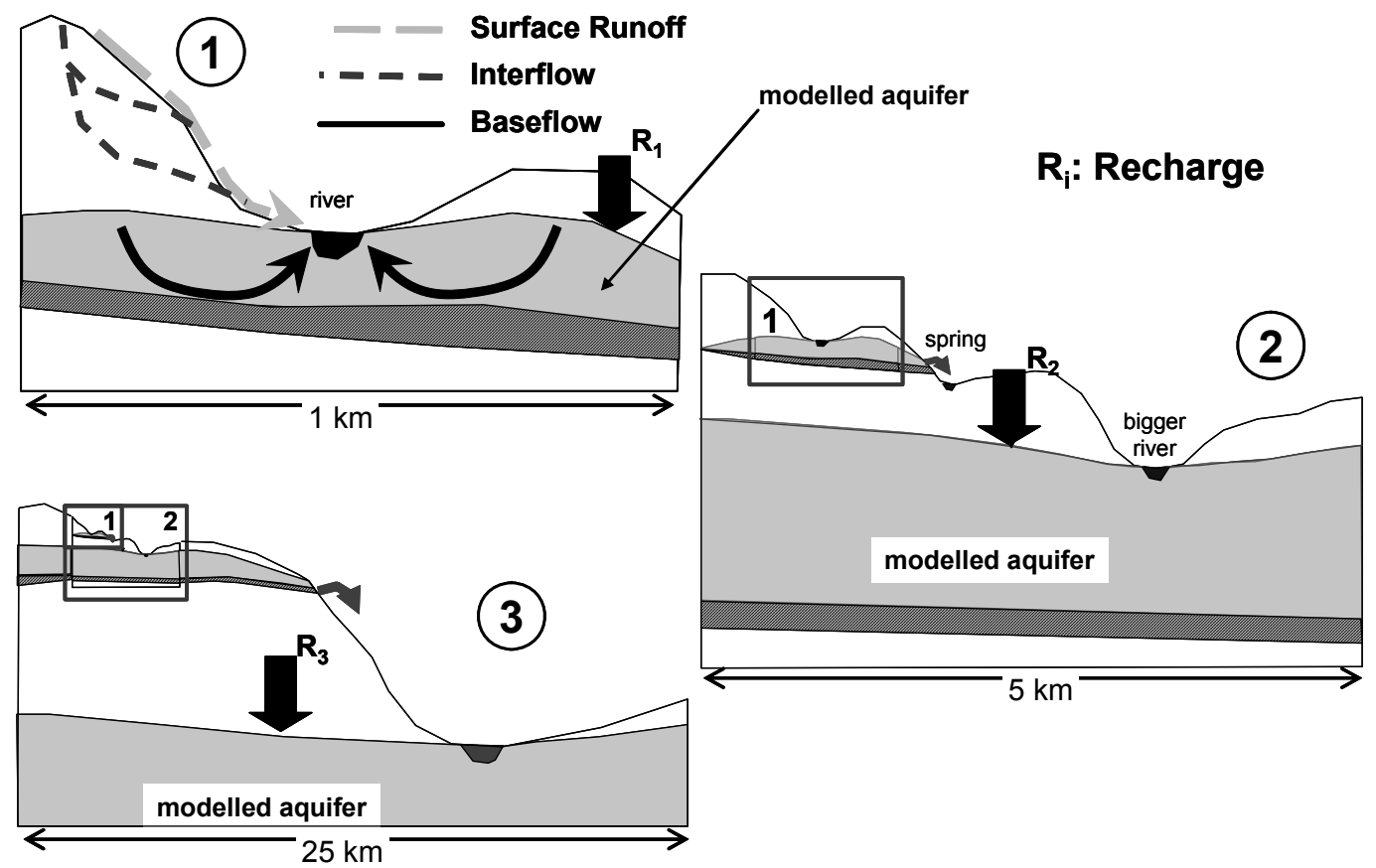

Fig. 6. Scale and context dependency of groundwater-related hydrological processes.

A source of severe problems in coupling surface (unsaturated flow) and subsurface (unsaturated flow) models is the fact that the unsaturated zone - in particularly on the regional scale - can be of considerable thickness (up to $1000 \mathrm{~m}$ and more). What is defined as the unsaturated zone depends of course always on the scale of the problem (see Fig. 5). Apart from the temporal effects this has on percolation, horizontal flow within this zone can lead to the result that water percolating through the upper part of the unsaturated zone (1 to $10 \mathrm{~m}$ ) will never or only partly reach the aquifer of interest. It is partly because this zone is inaccessible for measurements and partly because no branch of hydrological sciences feels responsible, that processes in this deep unsaturated zone (or transfer zone) are treated in a highly simplified or conceptual manner, no matter how sophisticated the models for the zones above or below might be.

From these considerations, extensive conclusions can be drawn. The relatively new concept of IWRM as well as Global Change research have raised the demand for models that can be applied on the regional scale and that allow an integrated view of all processes. Until now, most integrated (coupled) modelling approaches are based on the coupling of existing modelling concepts. Existing models are usually designed for a specific purpose and a specific scale. They follow a certain approach of process descriptions by including and calculating variables in a characteristic way. The problematic aspect when coupling such existing models is the question of how to make them work together in a consistent way. A review of available models in particular for groundwater flow simulation shows that the "old", wellestablished, well-validated and quite often relatively simple models that would be appropriate for the use on the large scale are very problem-specific and therefore not suitable for integration. On the other hand, newer model concepts, especially in the groundwater field, are much better suited for integration as they often can describe saturated as well as unsaturated flow. However, they are very parameter/variable demanding and are therefore not suitable for application on a regional scale.

Finally these considerations lead to the question of whether it always makes sense to follow the approach of coupling existing models in integrated modelling? A desirable alternative would be the development of new, fully integrated (holistic) concepts that are appropriately designed for the requirements of IWRM on a large scale. If this alternative proves impractical in view of the urgent demand for ready-to-use concepts, new sectoral model concepts customized for the application in integrated systems on the regional scale should be developed.

Edited by: R. Barthel, J. Götzinger, G. Hartmann, J. Jagelke, V. Rojanschi, and J. Wolf

Reviewed by: anonymous referees 


\section{References}

Andres, G. and Egger, R.: A new tritium interface method for determining the recharge rate of deep groundwater in the Bavarian Molasse Basin, J. Hydrol., 82(1/2), 27-38, 1985.

Bergström, S.: The HBV model, in: Computer Models of Watershed Hydrology, edited by: Singh, V. P., Water Resources Pub., Littleton, CO, 443-476, 1995.

Bronstert, A., Carrera, J., and Kabat, P.: Coupled Models for the Hydrological Cycle Integrating Atmosphere, Biosphere and Pedosphere, 240p., ISBN 3540223711, Berlin, 2005.

de Vries, J. J. and Simmers, I.: Groundwater recharge: an overview of processes and challenges, Hydrogeol. J., 10, 5-17, 2002.

Harter, T. and Hopmans, J. W.: Role of Vadose Zone Flow Processes in Regional Scale Hydrology: Review, Opportunities and Challenges, in: Unsaturated Zone Modeling: Progress, Applications, and Challenges, edited by: Feddes, R. A., de Rooij, G. H., and van Dam, J. C., Kluwer, 179-208, 2004.

Halford, K. J. and Mayer, G. C.: Problems associated with estimating ground water discharge and recharge from stream-discharge records, Ground Water, 38(3), 331-342, 2000.

Lemmelä, R. and Tattari, S.: Applications of transfer function and conceptual pulse models to the study of groundwater level fluctuation, Geophysica, 24(1-2), 33-46, 1988.
McDonald, M. G. and Harbaugh, A. W.: A modular threedimensional finite-difference ground-water flow model, Technical report, U.S. Geol. Survey, Reston, VA, USA, 1988.

Rauert, W., Wolf, M., Weise, S. M., Andres, G., and Egger, R.: Isotope-hydrogeological case study on the penetration of pollution into the deep Tertiary aquifer in the area of Munich, Germany, J. Contaminant Hydrol., 14(1), 15-38, 1993.

Sanford, W.: Recharge and groundwater models: an overview, Hydrogeol. J., 10, 110-120, 2002.

Scanlon, B. R., Healy, R. W., Cook, P. G.: Choosing appropriate techniques for quantifying groundwater recharge, Hydrogeol. J., 10, 18-39, 2002.

Seibert, J.: Multi-criteria calibration of a conceptual runoff model using a genetic algorithm, Hydrol. Earth Syst. Sci., 4(2), 215224, 2000.

Tallaksen, L. M.: A review of baseflow recession analysis, J. Hydrol., 165, 349-370, 1995.

Tankersley, C. D., Graham, W. D., and Hatfield, K.: Comparison of univariate and transfer function models of groundwater fluctuations, in: Water Resour. Res., 29(10), 3517-3533, 1993.

Vogel, R. M. and Kroll, C. N.: Estimation of Baseflow Recession Constants, Water Resour. Manag., 10, 303-320, 1996. 